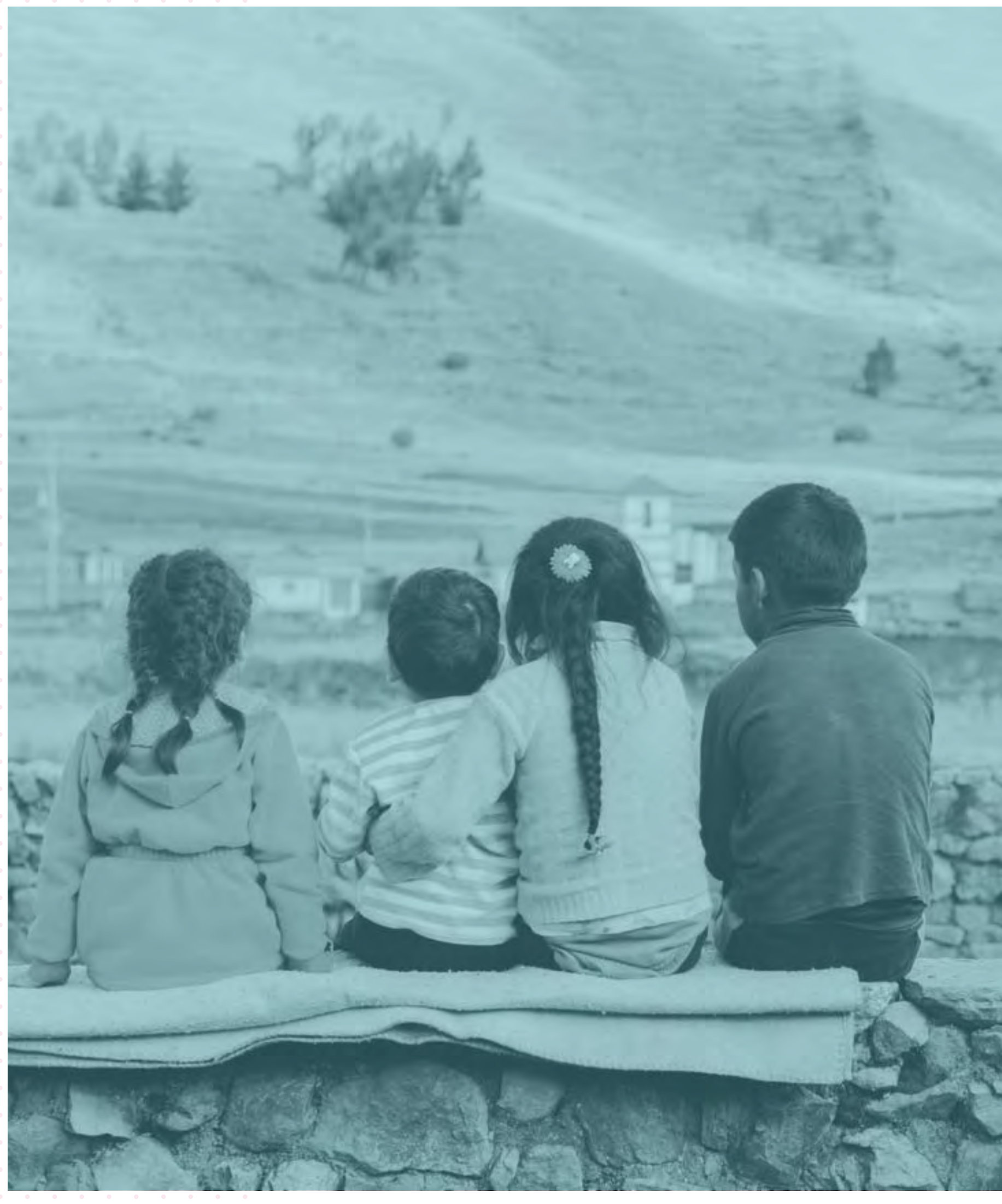




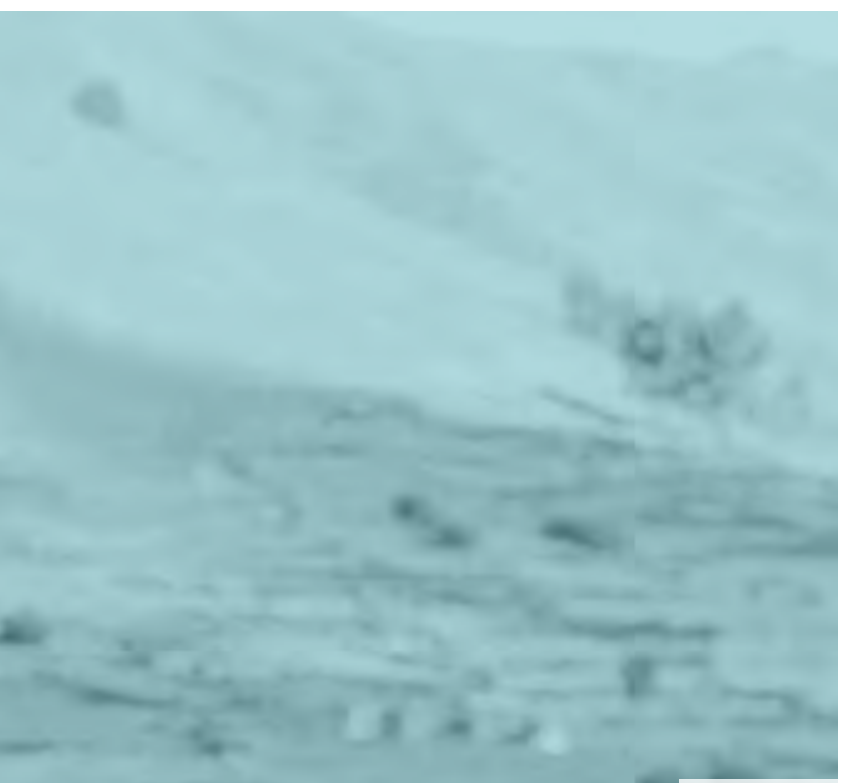

- artículo. 4

\section{Los niños y las constituciones}

Aiofe Nolan ${ }^{119}$ y Conor O'Mahony ${ }^{120}$

DOI: $10.53110 / g$ fit7271

A. Introducción: Más de 30 años después de la promulgación de la Convención de las Naciones Unidas sobre los Derechos del Niño (CDN), es cada vez más frecuente que las constituciones nacionales incluyan disposiciones específicas sobre los derechos del niño. Esto es especialmente cierto en situaciones en las que un país adopta una constitución completamente nueva; pero, adicionalmente, muchos países han enmendado las constituciones existentes para añadir nuevas provisiones sobre los derechos de los niños. La protección constitucional de los derechos de los niños también es objeto de un nuevo cuerpo de literatura y debates académicos. Este ensayo explorará brevemente algunas de las lecciones que podrían ser beneficiosas para los países que están considerando la constitucionalizarían de los derechos de los niños. Comenzará exponiendo los argumentos a favor de incluir una disposición específica sobre los derechos de los niños en una constitución nacional. A continuación, analizará las experiencias comparativas de la constitucionalización de los derechos de los niños en una variedad de países. Por último, considerará los puntos clave que debe considerar un país al inicio de un proceso conducente a la promulgación de una disposición constitucional dedicada a los derechos de los niños.

119 Profesora de Derecho Internacional de los Derechos Humanos y codirectora del Centro de Derecho de Derechos Humanos de la Universidad de Nottingham. También es vicepresidenta del Comité Europeo de Derechos Sociales, al que se incorporó en 2017.

120 Profesor de la Facultad de Derecho de University College Cork, donde enseña e investiga sobre derecho constitucional y derechos del niño. Fue nombrado Relator Especial sobre Protección Infantil por el Gobierno de Irlanda en 2019. 
B. Existen diversas razones por las que las disposiciones constitucionales dedicadas a proteger los derechos de los niños tienen potencial para avanzar sus derechos. El primero es el simbolismo del reconocimiento constitucional de que los niños son sujetos de derechos. Aunque la Convención de los Derechos del Niño (CDN) no requiere que los derechos de los niños estén protegidos a nivel constitucional, el Comité de los Derechos del Niño ha declarado, no obstante, que acoge con satisfacción la constitucionalización sobre la base de que ésta "contribuye a subrayar la idea esencial de la Convención: que los niños, al igual que los adultos, son titulares de los derechos humanos". ${ }^{121}$ Similarmente, JOHN TOBIN ha argumentado que la inclusión de disposiciones sobre derechos de los niños en las constituciones nacionales legitima el discurso político sobre los derechos de los niños. ${ }^{122}$

Un escéptico podría señalar que las garantías generales de derechos en una constitución suelen aplicarse tanto a los adultos como a los niños por igual. Sin embargo, la confianza en las disposiciones generales como el único vehículo para proporcionar protección constitucional de los derechos de los niños puede generar confusión sobre la aplicación precisa de esos derechos a los niños. ${ }^{123}$ Del mismo modo en que la CDN se consideró necesaria para asegurar que los niños pudieran disfrutar de igual acceso a los derechos protegidos por el derecho internacional de los derechos humanos, las constituciones nacionales pueden a menudo beneficiarse de disposiciones específicas destinadas a garantizar que los niños puedan disfrutar de igual acceso a los derechos constitucionales en general o a derechos específicos de particular relevancia para los niños que no están adecuadamente protegidos por otras disposiciones. ${ }^{124}$

Más aún, la ausencia de una protección constitucional específica de los derechos de los niños puede llevar a la subordinación de los intereses de los niños a los de los adultos, en particular en las jurisdicciones en que la constitución prevé firmemente los derechos de los padres y/o de la familia. El juez Albie Sachs, del Tribunal Constitucional Sudafricano, observó en una ocasión que si un niños se imagina constitucionalmente como un individuo con una personalidad distintiva, y no sólo como un adulto en miniatura esperando a alcanzar su tamaño completo, ella o él no puede ser tratado como mera extensión de sus progenitores; umbilicalmente destinado a hundirse o nadar con ellos. ${ }^{125}$ Esto es lo que puede ocurrir algunas veces cuando los niños están forzados a confiar en disposiciones constitucionales generales

\footnotetext{
121 Comité de los Derechos del Niño, 2003, pár. 21.

122 Tobin, 2005, pp. 86 - 126.

123 Véase Fetzer y Houlgate, 1997, p. 319; y Habashi et al., 2010, pp. 267-269

y 278-279.

124 Véase, por ejemplo, Comité de los Derechos del Niño, 2002, pár. 5.

125 S vs. M, 2008, pár. 18.
} 
de derechos que no fueron diseñadas con los niños en la mente y que invariablemente son reivindicadas por los padres. Varios jueces reconocidos que abogan por los derechos del niño han destacado cómo los litigios judiciales que se refieren claramente a temas de derechos de los niños pueden decidirse sin ninguna referencia a esos derechos, o incluso sin ninguna representación para el niño, y "por motivos elegido por los adultos". ${ }^{126}$ Si bien los intereses de los niños y de sus padres frecuentemente coinciden, este no es siempre el caso; ${ }^{127}$ y cuando no coinciden, los derechos constitucionales concedidos a los padres o a las familias pueden actuar como una barrera para la reivindicación de los derechos independientes de los niños. La incorporación de disposiciones específicas sobre la infancia en una constitución, junto con la protección constitucional de los principios generales de la CDN, como el principio del interés superior del niño y el derecho a ser oído, tiene el potencial de recalibrar el proceso de toma de decisiones para que los intereses y deseos de los niños pasen al primer plano. ${ }^{128}$

En segundo lugar, la constitucionalización de los derechos del niño tiene la ventaja de elevar su estatus al punto más alto del sistema legal. Esto conlleva la doble ventaja del afianzamiento (que hace más difícil su deterioro) ${ }^{129}$ y la supremacía (que hace posible hacer valer estos derechos frente a leyes y políticas inferiores en conflicto). Por lo tanto, las disposiciones constitucionales exigibles pueden ser una herramienta poderosa tanto para proteger los derechos de los niños existentes como para promover los que aún no han sido reconocidos. Las ventajas de la protección constitucional como medio para fomentar dichos derechos pueden verse incluso en ausencia de disposiciones específicas sobre derechos de los niños. Basándose en las disposiciones generales, la Corte Suprema de EE.UU. ha promovido notablemente los derechos de los niños en formas que no podrían haberse logrado a través del proceso político, en casos como Brown vs. Board of Education ${ }^{130}$ y Roper vs. Simmons. ${ }^{131}$ Este potencial se amplía cuando una constitución incluye disposiciones que protegen los derechos de los niños que no pueden ser protegidos mediante disposiciones generales de derechos, o protege principios más amplios de los derechos de los niños-como el principio del interés superior- que luego pueden ser invocados para pro-

126 Regina v. Secretary of State for Education and Employment and others (Respondents) ex parte Williamson (Appellant) and others, 2005. Ver también N \& Anor. v. Health Service Excecutive \& Ors, 2006, pp. 474-475.

127 Véase Nolan, 2011, pp. 43-92.

128 Sin embargo, hay que tener en cuenta que la indeterminación del principio del interés superior lo deja abierto a ser utilizado como vehículo para seguir haciendo valer los derechos de los padres, sobre la base de que hacerlo es en el interés superior del niño. Véase, por ejemplo, Bonthuys, 2006, pp. 3335.

129 Op. Cit. Habashi et al., 2010 p. 279. 
moverlos, ya sea por sí solos o en conjunto con las disposiciones de derechos generales. En Irlanda, por ejemplo, se ha avanzado más en favor de los derechos de los niños con discapacidad gracias a la litigación basada en el derecho constitucional a la educación que lo que nunca se consiguió a través de campañas políticas. ${ }^{132}$ En Sudáfrica, SLOTH-NIELSEN Y KRUUSE sostienen que el impacto de la constitucionalización de los derechos de los niños ha crecido exponencialmente hasta infundir un campo de actividad judicial dinámico y en expansión. ${ }^{133}$ Una amplia gama de actividad judicial progresista y amigable con los niños ha sido posible gracias al cambio jurídico y cultural producido por la inclusión de una disposición de los derechos de los niños detallada y exigible en la Constitución de Sudáfrica.

Finalmente, si se proporcionan los medios adecuados para su cumplimiento, la protección constitucional de los derechos de los niños puede ayudar a resolver el déficit democrático inherente al hecho de que los niños, en la mayor parte de sus vidas, no pueden votar. Los adultos pueden reclamar sus derechos por medios políticos, pero siguen disfrutando de los derechos constitucionales como una medida de seguridad en las circunstancias en que los medios democráticos son ineficaces. Cuando se trata de los niños, su privación de derechos civiles crea una situación en la que los medios políticos serán a menudo muy ineficaces para proteger sus derechos; en consecuencia, la red de seguridad de la aplicación constitucional parecería aún más necesaria. Así, de la misma manera que se puede argumentar que la ejecución judicial contra-mayoritaria de los derechos es más legítima en ciertas categorías de casos que involucran a adultos, ${ }^{134}$ se puede argumentar que dicha actividad judicial es particularmente legítima en el caso de los derechos de los niños. ${ }^{135}$

130 Brown vs. Board of Education, 1954, en la que se anularon las leyes que segregaban las escuelas por motivos de raza por constituir una violación de la cláusula de igualdad de protección de la Decimocuarta Enmienda de la Constitución de los Estados Unidos.

131 Roper vs. Simmons, 2005; en el que se anularon las leyes que preveían la pena de muerte para los delitos cometidos por menores de 18 años por constituir una violación de la prohibición de castigos crueles e inhumanos de la Octava Enmienda de la Constitución de los Estados Unidos. Para un análisis del enfoque del Tribunal Supremo de EE.UU. sobre los casos de derechos del niño, véase Fetzer y Houlgate, 1997, p. 319; y Houlgate, 1999, p. 77.

132 Véase O'Mahony, 2008, p. 125.

133 Sloth-Nielsen y Kruuse, 2013, pp. 646-677.

134 Ely, 1980.

135 Op. Cit. Nolan, 2011, pp. 43-133. Se hace un planteamiento similar en Comité de los Derechos del Niño, 2002, pár. 5. 
El alcance y la naturaleza de la protección constitucional de los derechos de los niños están determinados por una gran variedad de factores políticos, jurídicos, sociales y culturales. En algunos casos, los derechos constitucionales de los niños forman parte de un nuevo acuerdo constitucional. Tal fue el caso de Sudáfrica (1996), Bolivia (2009) y Kenia (2010). En otros países, como Irlanda y Noruega, ${ }^{136}$ los derechos de los niños se introdujeron en un marco constitucional preexistente, y por tanto tuvieron que ser interpretados en el contexto de los estándares constitucionales y la jurisprudencia existentes.

Como era de esperar, la casi universal adopción y ratificación de la CDN desde 1989 ha estimulado una mayor atención a la protección legal concedida a los derechos de los niños a nivel nacional. En algunos casos, la ratificación de la CDN ha resultado en la incorporación automática de los derechos de ese documento en las jerarquías constitucionales de los países (por ejemplo, Colombia y Argentina). ${ }^{137}$ En muchos otros casos, la CDN ha servido de base para los esfuerzos de los defensores para abogar por una mayor protección constitucional de los derechos de los niños mediante la incorporación de elementos de ese instrumento en las disposiciones constitucionales, ${ }^{138}$ tanto a nivel constitucional nacional como regional. ${ }^{139} \mathrm{El}$ creciente reconocimiento y protección de estos derechos en los sistemas jurídicos regionales de derechos humanos ${ }^{140}$ también ha influido en la evolución constitucional doméstica de los mismos. ${ }^{141}$

Dicho esto, la ratificación generalizada de la CDN no debe interpretarse como el reflejo de un consenso sobre la forma en los derechos protegidos

136 La Trigésima Primera Enmienda a la Constitución irlandesa supuso la introducción del artículo 42A en la Constitución, así como la supresión de una disposición preexistente, el artículo 42.5 que se refería a los niños. En 2014, el Parlamento noruego añadió a la Constitución la Parte E sobre derechos humanos (Carta de Derechos), incluyendo el artículo 104.

137 Véase, por ejemplo, la Constitución colombiana, artículo 93; la Constitución argentina, artículo 75(22); la Constitución venezolana, artículo 23.

138 Para el análisis de algunos de los numerosos contextos nacionales en los que esto ha ocurrido, véase, entre otros, Tobin 2005; Lundy et al., 2012.

139 Con respecto a este último punto, véase el proyecto de ley de incorporación de la Convención de las Naciones Unidas sobre los Derechos del Niño (Escocia) (2021), que fue aprobado por el Parlamento escocés el 16 de marzo de 2021. Aunque Escocia no tiene un documento constitucional codificado unificado, la Ley constituye una enmienda constitucional regional. Cabe señalar que la incorporación directa de la CDN en la legislación escocesa estaba sujeta a los límites de los poderes del Parlamento escocés en términos del pacto de devolución del Reino Unido.

140 Para más información sobre la protección regional de los derechos del niño, véase, por ejemplo, Nolan y Kilkelly, 2016, p. 296.

141 Véase, por ejemplo: Mezmur, 2020, p. 693.
C.

Experiencia comparada de constitucionalización de los derechos del niño 
por ella deben ser protegidos por las constituciones nacionales. ${ }^{142}$ En efecto, ni siquiera hay acuerdo sobre cómo evaluar el grado en que las constituciones específicas reflejan la CDN o un enfoque de "derechos del niño" en términos amplios, con múltiples tipologías e indicadores siendo propuestos por diferentes comentaristas. ${ }^{143}$

Sin embargo, está claro que hay una tendencia creciente a prestar más atención a los niños en las constituciones. Escribiendo en 2005, TOBIN enumeró tres tipos de enfoques constitucionales para lidiar con los niños. En primer lugar, la constitución del "niño invisible", en la que los niños no son vistos ni escuchados y no reciben ningún trato o reconocimiento especial. En segundo lugar, la constitución de la "protección especial", en virtud de la cual los niños reciben un reconocimiento especial dentro del texto debido a su vulnerabilidad y necesidad de atención y protección especial (lo que también puede considerarse un enfoque "asistencialista"). La lente principal a través de la cual el enfoque de "protección especial" ve la situación de los niños es la de los padres y a menudo son sus derechos los que más preocupan. Los niños son percibidos como objetos pasivos que necesitan una protección especial más que como sujetos activos. Por último, está la constitución de los "derechos del niño", en la que el reconocimiento especial de los niños se aborda en términos de derechos del niño, en lugar del enfoque asistencial que caracteriza su tratamiento en las constituciones de "protección especial". ${ }^{144}$ TOBIN ha argumentado -acertadamente- que hay un fuerte aspecto histórico o cronológico reflejado en estos tres enfoques. ${ }^{145}$

Aunque esta tipología no está exenta de problemas (sobre todo debido a la posible superposición y permeabilidad de las categorías, así como a la posibilidad de que las constituciones puedan contener disposiciones coherentes con más de una categoría), la identificación de TOBIN de la tendencia hacia una mayor visibilidad de los niños y sus derechos en las constituciones es acertada. Sin embargo, esta tendencia no implica necesariamente que se preste la misma atención a todos los diversos derechos concedidos a los niños en virtud de la CDN.

Dada las diferentes formas en que los comentaristas han clasificado las disposiciones relacionadas con los derechos del niño, no existe una análisis definitivo del grado de protección que estos derechos tienen en las constituciones de todo el mundo. Sin embargo, es posible identificar las prin-

\footnotetext{
142 O'Mahony, 2019, p. 401.

143 Véase, por ejemplo, Tobin, 2005; Habashi et al, 2010; O'Mahony, 2019.

144 Tobin, 2005, p. 109.

145 Ibíd., p. 94.
} 
cipales tendencias. Así, mientras que el derecho a la educación (explícitamente vinculado tanto a los niños como grupo como expresado en términos generales) ${ }^{146}$ y el derecho de los niños a la protección contra la violencia, el abuso o la explotación son características de un gran número de constituciones; ${ }^{147}$ los derechos relacionados con la participación de los niños han recibido mucho menos reconocimiento constitucional ${ }^{148}$ (para excepciones notables, véase Bolivia (2009) y la República Dominicana (2015))..$^{149}$ Por lo tanto, está claro que, incluso cuando un país se compromete a incluir los derechos del niño en su constitución, no se puede asumir que adoptará un enfoque holístico o exhaustivo con respecto a los derechos incluidos.

Dicho esto, desde 1989 ha habido una tendencia perceptible hacia las disposiciones que describen en detalle la protección de derechos para los niños (por ejemplo, Kenia, Ecuador, Colombia y Nepal). ${ }^{150}$ Esto ha sido una característica particular en las jurisdicciones en las que se han adoptado nuevas constituciones en su totalidad. En algunos casos, esto ha ocurrido cuando tales derechos forman parte de un esfuerzo general por colocar protecciones amplias de derechos humanos en el centro del esquema constitucional (por ejemplo, Timor-Leste, Fiji y Bolivia). ${ }^{151}$ En otros, la inclusión de los derechos de los niños refleja, al menos en parte, el reconocimiento por parte de los redactores de la constitución del daño particular sufrido por los niños como grupo dentro de esa jurisdicción (por ejemplo, Sudáfrica). ${ }^{152}$

Por supuesto, la redacción de las disposiciones relativas a los derechos del niño (o de las disposiciones relacionadas con derechos de los niños) no sirven por sí solas para garantizar que los mismos tengan un impacto significativo, tanto en el contexto del derecho constitucional como, en términos más generales, para garantizarlos en la jurisdicción en cuestión. Como señala O'MAHONY, el grado de reconocimiento expreso de los derechos del niño en las constituciones sólo cuenta una parte de la historia, ya que la inclusión de un derecho en un documento constitucional no da lugar auto-

146 Véase, por ejemplo, Heyman et al., 2014, p. 121.

147 Op. Cit., O'Mahony, 2019, p. 416.

148 Véase Op. Cit., Habashi et al., 2010, p. 279.

149 Artículo 59.V de la Constitución de Bolivia (2009); Constitución de la República Dominicana (2015), artículos 55(13) y 56(2).

150 Constitución de Kenia (2010), artículo 53; Constitución de Ecuador (2008), artículos 44-46; Constitución de Colombia (1991), artículo 44; Constitución de Nepal (2015), artículo 39.

151 Constitución de Timor-Leste (2002), artículo 18(2); Constitución de Fiji (2013), artículo 41; Constitución de Bolivia (2009), sección V sobre "Derechos de los niños, adolescentes y jóvenes".

152 Constitución de Sudáfrica, 1996, sección 28. 
máticamente a remedios en caso de que no se reivindique ese derecho. ${ }^{153}$ Las posibilidades aquí incluyen remedios administrativos, como el funcionamiento de un Ombudsman para los Niños, o una serie de remedios judiciales, incluyendo la indemnización por daños y perjuicios, la declaración de inconstitucionalidad, deberes de interpretación y medidas cautelares. ${ }^{154}$ De hecho, incluso en los casos en que los derechos del niño están integrados en el derecho constitucional de tal manera de hacerlos exigibles -en lugar de estar incluidos en los Principios Rectores de Política Social, que no son exigibles judicialmente, como es el caso de los derechos socioeconómicos del niño en las constituciones de Ghana (1996) ${ }^{155}$ y la India (1950), por ejemplo ${ }^{156}$ - la experiencia comparativa demuestra que ni siquiera las disposiciones más amplias y prescriptivas sobre estos derechos incluidas en una constitución serán capaces de transformar unilateralmente la cultura política y social de una jurisdicción para centrarlas en los derechos del niño. (Volveremos sobre este punto en la sección siguiente). Dicho esto, la falta de reconocimiento adecuado de los derechos del niño obstaculizará sin duda estos esfuerzos, debido al "vacío de derechos del niño" en el esquema constitucional que supondrá dicha omisión. Por lo tanto, la promulgación de disposiciones constitucionales específicas sigue siendo un paso importante en la protección de los derechos de los niños, sin perjuicio del hecho de que éstas deben ir acompañadas de estructuras jurídicas concretas para remediar las vulneraciones de esos derechos, así como de medidas "blandas" destinadas a incorporar los derechos de los niños en las culturas jurídicas y políticas.

\footnotetext{
153 Op. Cit., O'Mahony, 2019, p. 424.

154 Ibíd., p. 424-431.

155 Véase el apartado 2 del artículo 37 en el capítulo 6 sobre "The Directive Principles of State Policy". Otros derechos de los niños se recogen en los artículos 28 ("derechos del niño") y 25 ("derechos educativos") del capítulo quinto sobre "Fundamental Human Rights and Freedoms"

156 Véase Unni Krishnan, JP and others vs. State of Andhra Pradesh and others, 1993, en el que el Tribunal Supremo de la India sostuvo que el paso de 44 años desde la promulgación de la Constitución de la India había convertido efectivamente el derecho no justiciable a la educación de los niños menores de 14 años contemplado en el capítulo de los Principios Directivos de dicho instrumento en un derecho. El Estado respondió a esta declaración nueve años después en forma de la $86^{a}$ Ley de Enmienda de la Constitución de 2002 que, entre otras cosas, insertó el artículo 21A en la Constitución. Esta disposición establece que "el Estado proporcionará educación gratuita y obligatoria a todos los niños de seis a catorce años en la forma que el Estado pueda, por ley, determinar".
} 
En la práctica, ningún país comenzará realmente desde cero cuando se trata de constitucionalizar los derechos de los niños. Incluso en los casos en que estos derechos específicos no hayan aparecido previamente en los instrumentos constitucionales, el enfoque adoptado para los niños y sus derechos en cualquier proceso de constitucionalización se verá inevitablemente afectado por la historia, el contexto político, social y cultural de un país, incluyendo los acuerdos constitucionales preexistentes. Respecto a los acuerdos constitucionales preexistentes que no incluyen disposiciones sobre los derechos del niño, hay dos áreas en particular en las que los niños son abordados con frecuencia, aunque dichas disposiciones a menudo no están redactadas ni conceptualizadas en términos de derechos del niño: el derecho a la educación y los derechos de la familia. Este es el caso de Chile, por ejemplo. ${ }^{157}$

Cuando el reconocimiento constitucional adopta la forma de inserción de los derechos de los niños en un esquema constitucional existente, es vital que se preste la debida atención a la forma en que los derechos que han gozado de un reconocimiento previo (y las teorías del derecho constitucional y la jurisprudencia relacionadas con ellos) repercutirán en el alcance y el efecto constitucional de los derechos del niño en la práctica. Esto es crucial dados los posibles problemas que plantean estos derechos en cuanto a su interacción con las disposiciones no específicas para los niños, incluso en situaciones que implican una ponderación judicial de los derechos (en particular los derechos de los padres y las familias). ${ }^{158}$ Incluso cuando la constitucionalización de los derechos del niño se produce como parte de una nueva constitución, hay que tener cuidado de que la redacción de otros aspectos de ese documento no sirva para socavar los derechos específicos concedidos a los niños, ya sea permitiendo la subordinación de sus derechos a los de otros o perpetuando enfoques legales que no sean compatibles. Esto es particularmente cierto cuando quienes implementan, litigan y/o adjudican los derechos constitucionales pueden estar menos familiarizados con los derechos de los niños y con los problemas que enfrenta dicho colectivo (incluyendo los diferentes subgrupos de niños) como grupo social en términos de disfrute de sus derechos. Las posibles ramificaciones de un pasado que no adoptó un enfoque de derechos de los niños para las futuras disposiciones constitucionales sobre los derechos del niño deben reconocerse y abordarse.

157 Constitución de Chile (1980), artículos 19(10) y (11) (derecho a la educación) y artículos 1 y 19(4) (derechos de la familia).

158 Para un ejemplo útil de un tribunal que aborda la interacción de una disposición de derechos del niño recién introducida con disposiciones constitucionales y jurisprudencia preexistentes, véase In the Matter of JJ, 2021, pár. 124-151.
D.

¿Qué debe hacer

un país que

comienza de cero? 
En el apartado anterior se ha puesto de manifiesto el creciente reconocimiento constitucional de los derechos del niño en todo el mundo. Sin embargo, esto no refleja una tendencia general hacia una mayor participación de los niños en los procesos constitucionales. Esto no es de extrañar si se tiene en cuenta la limitada ciudadanía democrática de la que disfrutan los niños en todo el mundo, y los más pequeños en particular. ${ }^{159}$ Incluso en los casos en los que dichos procesos han sido (o han pretendido ser) consultivos y participativos (por ejemplo, mediante el uso de asambleas ciudadanas o foros constitucionales ${ }^{160}$ ), la diversidad se ha centrado generalmente en la gama de adultos representados ( $y$, en particular, en la inclusión de actores elegidos no pertenecientes a la élite), más que en la perspectiva de los niños. Esto es particularmente problemático dados los importantes inconvenientes que surgen con respecto a la representación efectiva de los niños y sus intereses por parte de los representantes electos adultos. ${ }^{161} \mathrm{Si}$ bien hay casos en los que los niños han desempeñado un papel en términos de impulsar el fortalecimiento de la protección constitucional de sus derechos (por ejemplo, Brasil, Nepal y Escocia), ${ }^{162}$ esto ha sido la excepción y no la norma, incluso cuando tales constituciones finalmente incluyen los derechos de participación de los niños (por ejemplo, Noruega (2014)). ${ }^{163}$ Para que los procesos de redacción de constituciones cumplan con los derechos de los niños, en lugar de limitarse a ellos, es crucial que dichos procesos se conceptualicen y operen de tal manera que hagan efectivas las obligaciones de los Estados Partes en virtud de la CDN. Tal vez el derecho más evidente en este contexto sea el derecho del niño a expresar sus opiniones en virtud del artículo 12 de la CDN. En este momento, existe un creciente conjunto de prácticas muy amplio sobre la participación de los niños con respecto a la ley, la política y otros procesos que pueden emplearse para garantizar que las opiniones de los niños sobre si las constituciones deben dar efecto a sus derechos y cómo hacerlo, sean tenidas en cuenta en la toma de decisiones relacionadas con la constitución. Si los niños y sus opiniones no están presentes (o no están efectivamente representados por apoderados o representantes adultos legítimos, como las organizaciones de derechos de los niños o los defensores de los niños) en la mesa constitucional, existe el riesgo inevitable de que sus derechos se pasen por alto o se subordinen a otras preocupaciones de mayor importancia para los participantes adultos en las negociaciones constitucionales.

159 Para más información, véase, por ejemplo, Nolan, 2011, pp. 49-93; Kulynych, 2001, p. 231; Rehfeld, 2011, p. 141; Wall, 2012, p. 86.

160 Entre los ejemplos más notables se encuentran los de Islandia e Irlanda, ninguno de los cuales tuvo como resultado (ni pretendía tenerlo) una mayor protección de los derechos de los niños. Para saber más sobre estas experiencias, consulte Thorgeirsdóttir, 2015; Gylfason, 2013; Carolan, 2015, 733.

161 Op. Cit., Nolan, 2011, capítulo 2. 
Independientemente de la forma que los derechos de los niños adopten dentro de un marco constitucional, es crucial que la mayor protección sobre el papel vaya acompañada de las medidas necesarias para garantizar que los diversos actores responsables de hacer efectivos esos derechos estén adecuadamente equipados para hacerlo. Éstas deben incluir planes y mecanismos (incluidos los extrajurídicos) para garantizar que los derechos de los niños se incorporen a la práctica de los agentes -ejecutivos, legislativos y administrativos- que tienen la responsabilidad principal de garantizar la aplicación de los derechos de los niños. Los redactores de las constituciones suelen ser abogados que, comprensiblemente, debido a sus prejuicios disciplinarios, centran gran parte de su atención en los tribunales.

No hay duda de que los tribunales desempeñarán un papel crucial de supervisión con respecto a los derechos constitucionales de los niños y esto hace que la creación de capacidad judicial adecuada sobre los derechos de los niños sea una prioridad urgente. Sin embargo, las constituciones están destinadas a constituir el marco central de un país para la elaboración de leyes y políticas. Por lo tanto, no centrarse en el papel de los que llevan a cabo ese trabajo limitará inevitablemente el impacto del reconocimiento constitucional de los derechos de los niños. Aunque los mecanismos eficaces de rendición de cuentas son cruciales para garantizar la reivindicación de dichos derechos, esta rendición de cuentas es reactiva y surge una vez que se ha producido un fracaso en términos de derechos constitucionales de los niños. Las medidas necesarias para garantizar la integración de los derechos de los niños en el trabajo cotidiano de los políticos y otros actores responsables de garantizar dichos derechos -que probablemente incluyen la educación y el desarrollo de capacidades, planes de derechos del niño, evaluaciones del impacto de los derechos de los niños, así como los recursos necesarios para garantizarlos- ciertamente no tienen por qué especificarse en el propio documento constitucional. Sin embargo, es vital que tanto los que redactan como los que hacen efectivas las protecciones de los derechos constitucionales de los niños comprendan que, sin tales medidas, la desventaja sistémica y estructural a la que se enfrentan muchos niños en la sociedad no se abordará, independientemente de lo expansiva y holística que sea la redacción constitucional.

162 Véase, por ejemplo, Rizzini y Klees, 2010; World Vision International, 2011. Cabe señalar que el proceso constitucional en Nepal se descarriló posteriormente y la nueva constitución no se adoptó hasta septiembre de 2015. En Escocia, para fundamentar plenamente su examen del proyecto de ley de incorporación de la CDN (Escocia), el Comité de Igualdad y Derechos Humanos ha llevado a cabo sesiones virtuales de divulgación con niños y jóvenes, facilitadas y organizadas por grupos de niños y jóvenes:https://archive2021. parliament.scot/parliamentarybusiness/currentcommittees/115977.aspx (consultado el 21 de abril de 2021).

163 Véase, por ejemplo, Haugli, 2019, pp. 39, 42-43. 
E. Este breve ensayo ha argumentado que hay razones de peso para que las constituciones nacionales incluyan disposiciones específicas sobre los derechos del niño. Su inclusión sirve para legitimarlos, dándoles un estatus equivalente al de los derechos de los adultos y creando un punto focal para la defensa política y legal; aporta los beneficios del afianzamiento y la supremacía, y ayuda a contrarrestar el déficit democrático inherente al hecho de que los niños no pueden votar, lo que deja sus derechos vulnerables a la negligencia política. Sin embargo, la inclusión de los derechos del niño en una constitución nacional es sólo un punto de partida. Los beneficios mencionados anteriormente sólo se acumulan si se cumplen una serie de condiciones.

En primer lugar, la disposición debe redactarse de manera que refleje el enfoque de los derechos de los niños previsto en la CDN y evite adoptar un enfoque paternalista que considere a los niños como objetos que necesitan protección en lugar de como agentes y titulares de derechos. En segundo lugar, los derechos de los niños deben ir acompañados de recursos efectivos; la ausencia de recursos permitirá que estos derechos sean violados con impunidad y los convertirá en algo simbólico en lugar de algo real. Por último, las reformas legales deben ir acompañadas de un programa más amplio de medidas destinadas a sensibilizar a políticos, administradores, jueces y abogados sobre los derechos de los niños. Esto es especialmente importante en los países en los que estos derechos se añaden a un marco constitucional preexistente en lugar de incorporarse a un documento completamente nuevo. Esto servirá tanto para hacer menos probable que se produzcan violaciones de derechos, como para que se concedan remedios significativos para las mismas. 


\section{- BIBLIOGRAFIA}

Bonthuys, E. (2006)

'The Best Interests of the Child in the South African Constitution', International Journal of Law, Policy and the Family, 20(1):23-43.

Brown v. Board of Education of Topeka (1954)

Corte Suprema de Estados Unidos. 347 U.S. 483.

Carolan, E. (2015)

'Ireland's Constitutional Convention: Behind the hype about citizen-led constitutional change', International Journal of Constitutional Law, 13(3):733-748.

\section{Comité de los Derechos del Niño (20013)}

Observación General No 5 (2003) Medidas generales de aplicación de la Convención sobre los Derechos del Niño (artículos 4 y 42 y párrafo 6 del artículo 44) Documento No. CRC/GC/2003/5.

\section{Comité de los Derechos del Niño (2002)}

Observación General Nº 2 (2002) El papel de las instituciones nacionales independientes de derechos humanos en la promoción y protección de los derechos del niño. Documento No. CRC/GC/2002/2.

Ely, J. (1980)

Democracy and Distrust: A Theory of Judicial Review. Cambridge: Harvard University Press.

Fetzer, P. y Houlgate, L. (1997)

'A new theory of children's rights', International Journal of Children's Rights, $5(3)$.

\section{Gylfason, T. (2012)}

'From Collapse to Constitution: The Case of Iceland'. CESifo Working Paper Series No. 3770. Disponible en: https://ssrn.com/abstract=2034241 (Consulta: 23 agosto 2021).

Habashi, J. et al. (2010)

'Constitutional Analysis: A Proclamation of Children's Right to Protection, Provision, and Participation', International Journal of Children's Rights, 18(2):267290.

\section{Haugli, T. (2019)}

'Constitutional Rights for Children in Norway', en Haugli, T. et al. (eds.) Children's Constitutional Rights in the Nordic Countries. Leiden: Brill, pp. 39-57.

Heyman, J. et al. (2014)

'Constitutional rights to education and their relationship to national policy and school enrolment', International Journal of Educational Development, 39:121-131. 
Houlgate, L. (1999)

'Three Concepts of Children's Rights: Reflections on the Enjoyment Theory', Journal of Constitutional Law, 2(1):77-94.

In the Matter of JJ (2021)

Corte Suprema de Irlanda. IESC 1.

Kulynych, J. (2001)

'No Playing in the Public Sphere: Democratic Theory and the exclusion of Children', Social Theory and Practice, 27(2): 231-264.

Lundy, L. et al. (2012)

The UN Convention on the Rights of the Child: A Study of Legal Implementation in 12 Countries. Florence: UNICEF Innoccenti.

Mezmur, B. (2020)

'The African Children's Charter @ 30: A distinction without a difference?', International Journal of Children's Rights, 28(4):693-714.

N \& Anor. v. Health Service Excecutive \& Ors. (2006)

Corte Suprema de Irlanda. 4 IR 464. 474-475.

Nolan, A. (2011)

Children's Socio-Economic Rights, Democracy and the Courts. Oxford: Hart Publishing.

Nolan, A. y Kilkelly, U. (2016)

'Children's Rights under Regional Human Rights Law - A Tale of Harmonisation?', en Buckley, C. et al (eds), Towards Convergence in International Human Rights Law: Approaches of Regional and International Systems. Leiden: Brill.

O’Mahony, C. (2008)

'Constitutionalism and Legislation in Special Educational Needs Law: An Anglo-Irish Comparison', Public Law, 1.

O’Mahony, C. (2019)

'Constitutional Protection of Children's Rights: Visibility, Agency and Enforceability', Human Rights Law Review, 19(3):401-434.

Paganetto, L. (2013)

Public Debt, Global Governance and Economic Dynamism. Italy: SpringerVerlag.

Regina v.

Secretary of State for Education and Employment and others (Respondents) ex parte Williamson (Appellant) and others (2005) Cámara de los Lores. UKHL 15 [71]. 
Rehfeld, A. (2011)

'The Child as Democratic Citizen', The Annals of the American Academy of Political and Social Science, 633(1).

Rizzini, I. y Klees, S. (2010)

'Children's Involvement in the Making of the New Constitution of Brazil', Cultural Survival Quarterly, 24(2). Disponible en: https://www.culturalsurvival.org/ author/steven-j (Consulta: 21 abril 2021).

Roper v. Simmons (2005)

Corte Suprema de Estados Unidos. 543 U.S. 551.

S vs. M (2008)

Corte Constitucional de Sudáfrica. Centre for Child Law as Amicus Curiae. [2007] ZACC 18, 2008 (3) SA 232 (CC), 2007 (12) BCLR 1312 (CC).

Sloth-Nielsen, J. y Kruuse, H. (2013)

'A Maturing Manifesto: The Constitutionalisation of Children's Rights in South African Jurisprudence 2007-2012', International Journal of Children's Rights, 21(4):646-678.

Thorgeirsdóttir, H. (2015)

The Icelandic Constitutional Experiment. Conference Paper Disponible en: https://www.venice.coe.int/webforms/documents/?pdf=CDL-PI(2015)020-e (Consulta: 24 agosto 2021).

Tobin, J. (2005)

'Increasingly seen and heard: the constitutional recognition of children's rights', South African Journal on Human Rights, 21(1):86-126.

Unni Krishnan, JP and others vs. State of Andhra Pradesh and others (1993) Corte Suprema de India. AlR 217.

Wall, J. (2012)

'Can democracy represent children? Toward a politics of difference', Childhood, 19(1):86-100.

World Vision International (2011)

Ensuring Child Rights in the Constitution of Nepal. Disponible en: https:// www.wvi.org/nepal/article/ensuring-child-rights-new-constitution-nepal (Consulta: 21 abril 2021). 